\title{
A Study on the Chemical Cleaning Process and Its Qualification Test by Eddy Current Testing
}

\author{
Ki Seok Shin* ${ }^{\dagger}$, Keun Young Cheon*, Min Woo Nam* and Kyong Mahn Min**
}

\begin{abstract}
Steam Generator (SG) tube, as a barrier isolating the primary coolant system from the secondary side of nuclear power plants (NPP), must maintain the structural integrity for the public safety and their efficient power generation. So, SG tubes are subject to the periodic examination and the repairs if needed so that any defective tubes are not in service. Recently, corrosion related degradations were detected in the tubes of the domestic OPR-1000 NPP, as a form of axially oriented outer diameter stress corrosion cracking (ODSCC). According to the studies on the factors causing the heat fouling as well as developing corrosion cracking, densely scaled deposits on the secondary side of the SG tubes are mainly known to be problematic causing the adverse impacts against the soundness of the SG tubes [1]. Therefore, the processes of various cleaning methods efficiently to dissolve and remove the deposits have been applied as well as it is imperative to maintain the structural integrity of the tubes after exposing to the cleaning agent. So qualification test (QT) should be carried out to assess the perfection of the chemical cleaning and QT is to apply the processes and to do ECT. In this paper, the chemical cleaning processes to dissolve and remove the scaled deposits are introduced and results of ECT on the artificial crack specimens to determine the effectiveness of those processes are represented.
\end{abstract}

Keywords: Steam Generator (SG), Eddy Current Testing (ECT), Stress Corrosion Cracking (SCC), Chemical Cleaning, Qualification Testing (QT)

\section{Introduction}

Chemical cleaning processes to remove sludge piles on the secondary side of the SG tubes have been developed and applied to PWR plants in the United States and other European and Asian countries [2-6]. Two types of chemical cleaning processes were independently developed by the EPRI and the AREVA (former KWU) and each process showed good performance record [7].

For this paper, EPRI process was applied and the test results were reviewed with respect to the impact to the defects which were artificially fabricated in the form of axial notches on the SG tubes. ECT was chosen to demonstrate the effectiveness of the QT.

\section{Chemical Cleaning Processes [8]}

The chemical cleaning processes mainly consist of two steps. These are iron and copper cleaning steps and also applicable respectively or in combination, depending on the composite of the deposit. Currently typical techniques are the EPRI process and the KWU, developed by EPRI and Framatome ANP, respectively. Fig. 1 and 2 are their schematic diagrams.

\subsection{EPRI Process}

The iron step of the EPRI process takes tens of hours in the range of 363 to $393 \mathrm{~K}$ and an inhibitor is added in the solution to deter the corrosion of the component materials. In order

[Received: October 14, 2013, Revised: December 2, 2013, Accepted: December 14, 2013] *Central Research Institute, KHNP Co. Ltd. Daejeon 305-343, Korea **UMI Inc., Daejeon 305-811, Korea †Corresponding Author: shinsks@khnp.co.kr

(c) 2013, Korean Society for Nondestructive Testing 


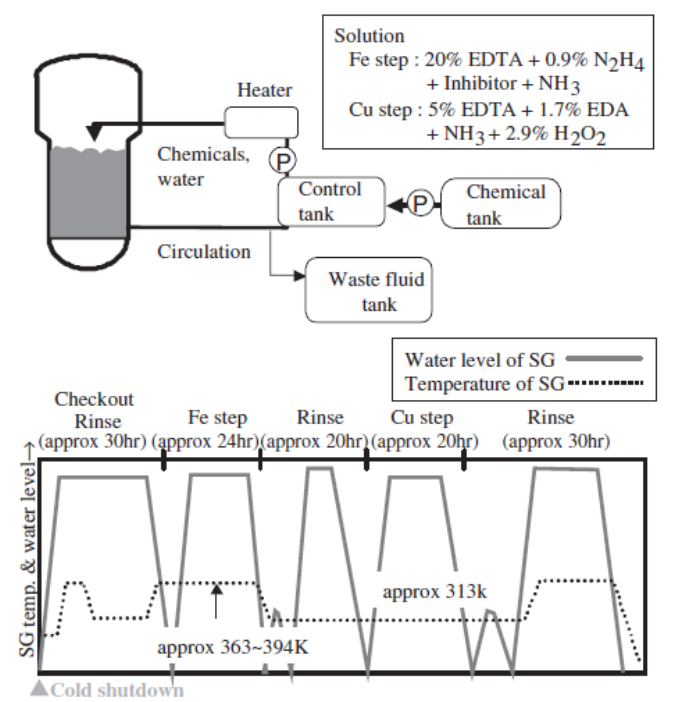

Fig. 1 Schematic diagram of the EPRI chemical cleaning process

to dissolve sludge piles, an excessive amount of EDTA (ethylene diamine tetraacetic acid) is injected.

As EPRI process is applicable only after the plant shutdown, an supplemental apparatus, such as heater and pump are necessarily installed in the cleaning system. The completion of the iron step is determined on the change of iron concentration in solution [3]. To monitor the corrosion of the carbon steel, affected by the inhibitor decomposition, two types of electrochemical corrosion monitoring techniques are employed. One is the linear polarization (LPR) method and the other is zero resistance ammetry (ZRA). The former is applied to estimate the corrosion behavior of the carbon steel, and the latter is applied to estimate galvanic corrosion behavior [9]. The copper step is carried out as a form of the chelated compound and subsequently being oxidized to copper ions. For maintaining oxidizing condition, hydrogen peroxide $\left(\mathrm{H}_{2} \mathrm{O}_{2}\right)$ is injected $[3,10]$.

\subsection{KWU Process}

In the KWU process for iron step, ammonium-

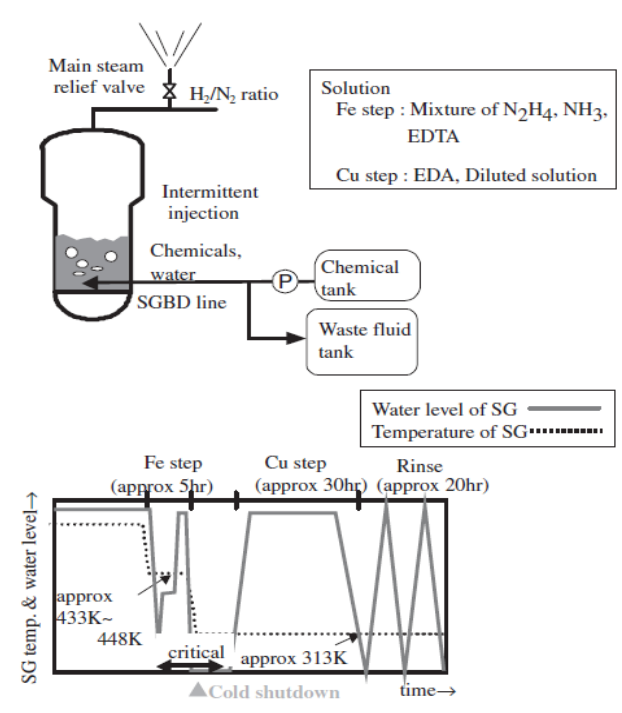

Fig. 2 Schematic diagram of the KWU chemical cleaning process

based EDTA is used as a chelate and a high concentration of EDTA solution is injected for several times and the temperature is maintained between 433 and $448 \mathrm{~K}$ without an inhibitor. Comparing with EPRI process, KWU is very simple, because solution temperature is controlled by the primary coolant temperature during the plant shutdown process and the auxiliary heater is not introduced.

To avoid the corrosion of component materials and maintain cleaning effectiveness, the injected quantity of EDTA should be made equivalent to that of sludge. The solution is stirred by boiling it. Gas monitoring, or $\mathrm{H}_{2} / \mathrm{N}_{2}$ ratio monitoring is performed to measure EDTA injection and to determine the end of the iron step [2]. The $\mathrm{H}_{2}$ is generated when the carbon steel is corroded and $\mathrm{N}_{2}$ represents the dissolution of the sludge pile. At the end of the iron step, $\mathrm{H}_{2} / \mathrm{N}_{2}$, ratio becomes higher due to the residual EDTA reaction with the iron [6]. The iron step is followed by the copper step. EDA (ethylene diamine acid) is introduced as a chelate and air is injected in the SG to maintain the oxidation atmosphere and to stir the solution. 


\section{Experiments}

\subsection{Specimen Preparation}

The SG tubes applied to the QT are made of Alloy600 HTMA (high temperature mill annealing) and fabricated by Valinox Nucleaire in France. The Valinox Nucleaire supplied the SG tubes for domestic OPR-1000 model NPP of Hanbit (former Yonggwang) unit 5 \& 6 , Hanul (former Ulchin) unit 3 and Shin-Kori unit 1 \& 2. The simplified processes of specimen fabrication are as follows. Initially the bare specimens were exposed to the environment for the artificial chemical corrosion and the reaction was immediately halted, provided that thorough penetration was confirmed by the solution reaction. For this reason, all flaws on the 8

Table 1 Specific description of the specimens

\begin{tabular}{|l|l|}
\hline \multicolumn{1}{|c|}{ Specimen } & \multicolumn{1}{c|}{ Description } \\
\hline \hline Material & Alloy600 HTMA \\
\hline Supplier & Valinox Nucleaire(France) \\
\hline Outer Diameter(OD) & 0.750 inch. \\
\hline Thickness & 0.042 inch \\
\hline Flaw Type & OD Axial SCC \\
\hline Flaw Fabrication & KAERI \\
\hline
\end{tabular}

specimens can be considered as thoroughly penetrated cracking defects. Prior to carrying out the QT, the specific information of the pre-cracked specimens was acquired by visual and ECT examinations. The same examinations were performed after the QT as well. The specific description and flaw fabrication process of the specimens are shown in Table 1 and 2, respectively. Fig. 3 shows the collection of the pre-cracked QT specimens

\subsection{Chemical Cleaning QT}

In order to clarify the impact to the structural integrity of the SG tubes due to the chemical cleaning, the autoclave apparatus simulating EPRI chemical cleaning process was assembled and the 8 pre-cracked QT specimens were processed per

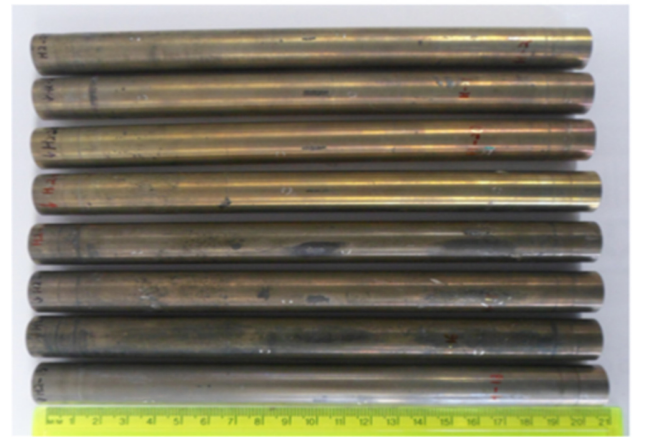

Fig. 3 Pre-cracked QT specimens

Table 2 Summary of the test specimen fabrication process

\begin{tabular}{|c|c|c|c|c|c|}
\hline \multirow{2}{*}{ Specimen } & \multicolumn{2}{|c|}{ Test method } & \multicolumn{2}{|c|}{ Complete Condition } & \multirow{2}{*}{ Heat treatment } \\
\hline & Method & No. & $\Delta \mathrm{nV}$ Value & Penetration & \\
\hline "HTMA2-13 & \multirow{8}{*}{ RT Acidic } & \multirow{4}{*}{6} & $10 \mathrm{nV}$ & " Confirmed & \multirow{8}{*}{$\left.\mathrm{SEN}^{1)}>\mathrm{ACT}-1^{2)}>\mathrm{ECT}^{3)}>\mathrm{TT}^{4}\right)>\mathrm{ECT} 2$} \\
\hline HTMA2-16 & & & $8 \mathrm{nV}$ & N/A & \\
\hline HTMA2-17 & & & $15 \mathrm{nV}$ & Confirmed & \\
\hline HTMA2-18 & & & $17 \mathrm{nV}$ & Confirmed & \\
\hline HTMA2-19 & & \multirow{4}{*}{7} & $11 \mathrm{nV}$ & Confirmed & \\
\hline HTMA2-20 & & & $29 n V$ & Confirmed & \\
\hline HTMA2-21 & & & $21 n V$ & Confirmed & \\
\hline HTMA2-25 & & & $19 n V$ & Confirmed & \\
\hline \multicolumn{6}{|c|}{$\begin{array}{l}\text { 1) SEN: Sensitization @600C, 30h } \\
\text { 2) ACT-1: Crack fabrication in acidic solution at } 25 \mathrm{C}, 14 \mathrm{MPa} \\
\text { 3) ECT: Eddy Current Testing } \\
\text { 4) Thermal treatment @ } 720 \mathrm{C}, 12 \mathrm{~h}\end{array}$} \\
\hline
\end{tabular}


chemical cleaning procedure [11]. As described above, the EPRI process has been world-widely adopted and applied due to the definite advantage of the proven negligible impact on the plant component and SG tubing materials as well as the excellent performance for removal of accumulated sludge piles. Fig. 4 is the schematic illustration of the simplified EPRI chemical

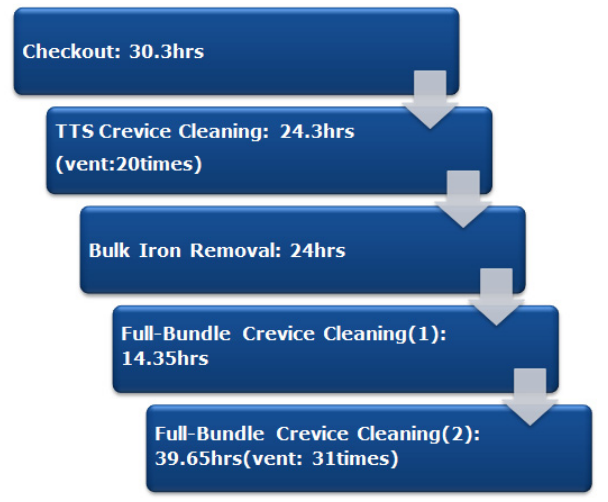

Fig. 4 Schematic illustration of the EPRI process

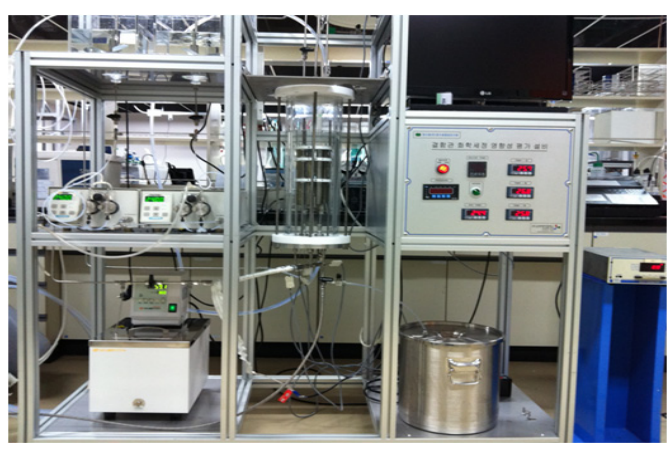

Fig. 5 QT apparatus simulating EPRI process

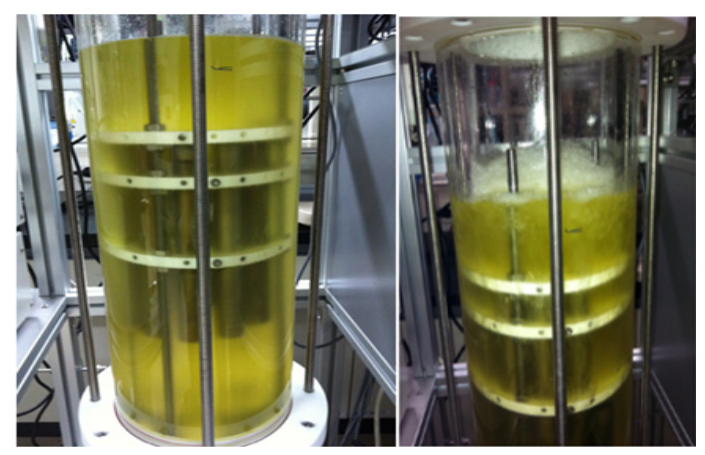

Fig. 6 Cleaning solution baths of the $\operatorname{dipped}(\mathrm{L})$ and rinsing $(R)$ of the specimens cleaning process and Fig. 5 is the photo of its QT experimental apparatus. Fig. 6 shows cleaning solution baths on the dipping and rinsing process of the specimens.

\subsection{Eddy Current Testing}

The effectiveness of the chemical cleaning to the tube with artificial crack was examined and

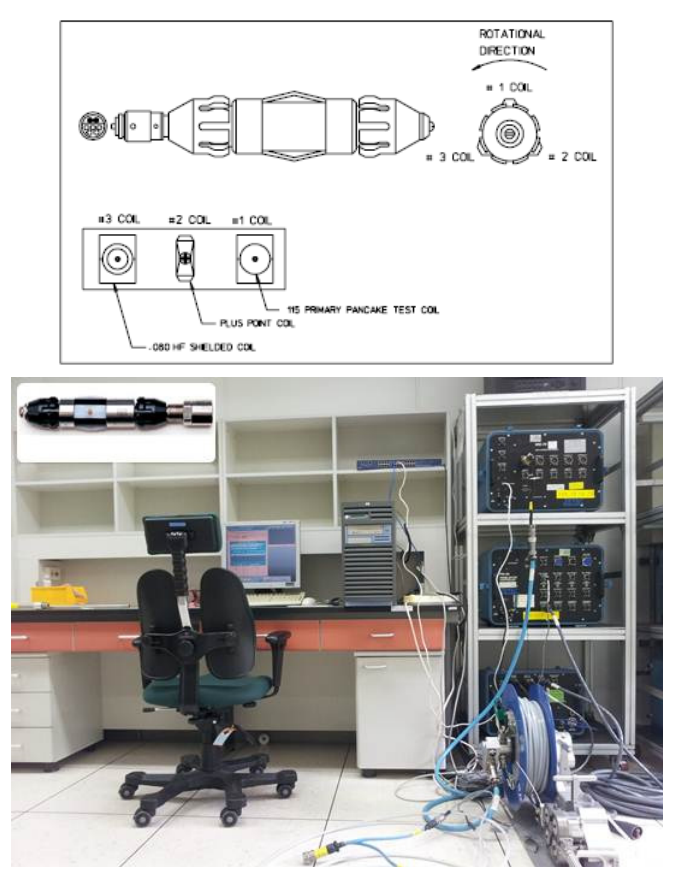

Fig. 7. ECT system w/ MRPC configuration(upper)

Table 3 ECT conditions of data Acq. and analysis

\begin{tabular}{|c|c|c|}
\hline \multicolumn{2}{|c|}{ Items } & Description \\
\hline \multirow{6}{*}{ Data $\mathrm{AC}$} & Specimen & $\begin{array}{l}8 \text { OD Axial Notch Tubes } \\
\text { ID: H2-13,16,17,18,19,20,21,25 }\end{array}$ \\
\hline & STD Tube & Alloy600 HTMA EDM Notch \\
\hline & Probe & 3C MRPC (ZETEC) \\
\hline & Freq.(kHz) & $400,300,100,20,700$ \\
\hline & Tester & $\begin{array}{l}\text { MIZ-70(ZETEC) PM3A, 10D } \\
\text { PP }\end{array}$ \\
\hline & $\mathrm{S} / \mathrm{W}$ & Eddynet 11i (ZETEC) \\
\hline Data AN & $\mathrm{S} / \mathrm{W}$ & Eddynet 11i (ZETEC) \\
\hline \multicolumn{3}{|c|}{$\begin{array}{l}\text { * The conditions not described above were basically } \\
\text { conformed with those of site specific data } \\
\text { acquisition and analysis guidelines. }\end{array}$} \\
\hline
\end{tabular}


verified by the application of the ECT. The considerations of the effectiveness are possibility of the newly formed corrosion cracking, and propagation and growth rate of the pre-cracked defects. Data acquisition unit and software is ZETEC's MIZ-70 and Eddynet11i, respectively. The testing probe is ZETEC's MRPC ${ }^{\circledR}$ (motorized rotating pancake coils), which is composed of 3 coils (unshielded pancake (P115A), point (PP11A) and high frequency pancake (SB080B), $120^{\circ}$ apart on the same circumferential plane. These multi coils scan helically being contacted with the inner surface of the tube and detects all the directional SCC defects. The ECT was implemented and performed in the same way as currently applied in the in-service inspection (ISI) of NPP. The configurations of ECT system and MRPC $^{\circledR}$ are shown in Fig. 7 and the specifics of the inspection is summarized in Table 2 .

\section{Results}

In order to validate a chemical cleaning efficiency on the tubes with artificial crack the EC signal characteristic variables, i.e. amplitude and shape of the signal were measured and compared with both data before and after cleaning process. The test was performed two times, due to the problems related to the specimen and testing system conditions. Results from the $1^{\text {st }}$ and $2^{\text {nd }}$ test were stated as follows.

\subsection{First Testing}

Comparing the differences between the signal readings about the amplitudes and depths from pre and post cleaning process, the signal amplitude of the post cleaning was slightly increased as much as $0.38 \mathrm{~V}$ and the depth of the defect measured by the authorized ETSS (examination technique specification sheet) was also increased approximately 7 of the pre cleaning value. To determine the cause of the increased signal amplitude and defect depth, the noticeable magnetite signals were apparently observed and measured at the pre QT. The amplitude of the magnetite signals were decreased at the post QT. The changes were 0.19 Volts of H2-19 and 1.5 Volts of H2-21 specimens respectively. The changes of the EC results on the specimens were presumably attributed from the residual magnetite distorting

Table 4 ECT results of $1^{\text {st }}$ pre/post QT specimens

\begin{tabular}{|c|c|c|c|c|c|c|}
\hline \multirow{2}{*}{ Spec. } & \multicolumn{2}{|c|}{ Pre-QT } & \multicolumn{2}{c|}{ Post-QT } & \multicolumn{2}{c|}{ Deviation } \\
\cline { 2 - 7 } & Amp. & \%TWH & Amp. & \%TWH & Amp. & \%TWH \\
\hline \hline H2-13 & 0.46 & 43 & 0.69 & 50 & 0.23 & 7 \\
\hline H2-16 & \multicolumn{5}{|c|}{ Not measurable(Attributed to noise) } \\
\hline H2-17 & 0.80 & 53 & 0.59 & 47 & -0.21 & -6 \\
\hline H2-18 & 1.37 & 64 & 2.10 & 73 & 0.73 & 9 \\
\hline H2-19 & 0.96 & 57 & 0.98 & 57 & 0.02 & - \\
\hline H2-20 & 0.95 & 56 & 1.25 & 62 & 0.30 & 6 \\
\hline H2-21 & 0.99 & 57 & 1.42 & 65 & 0.43 & 8 \\
\hline H2-25 & 0.76 & 51 & 0.92 & 56 & 0.21 & 5 \\
\hline
\end{tabular}

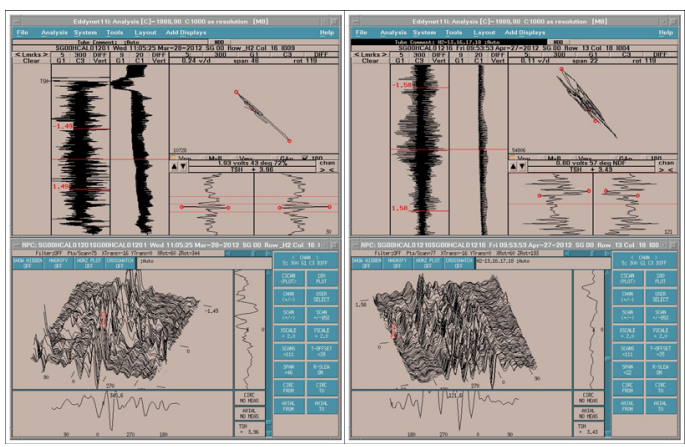

Fig. 8 EC C-scan of $1^{\text {st }}$ QT of pre(L)/post(R) H2-16
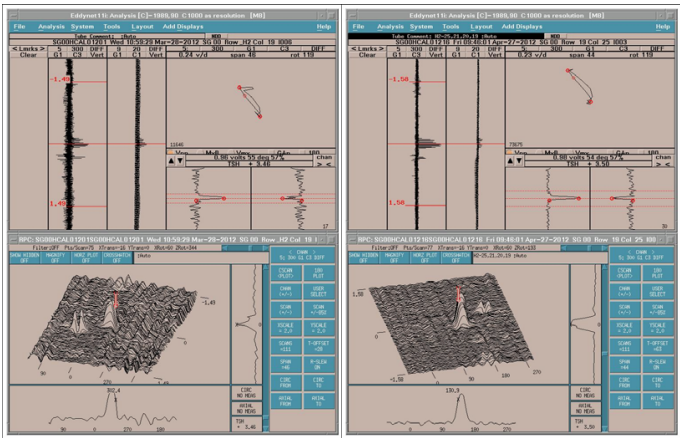

Fig. 9 EC C-scan of $1^{\text {st }}$ QT of pre(L)/post(R) H2-19 
the signals, or permeability variation (PV) or electromagnetic noise remaining in the pre QT specimens. The ECT results of the $1^{\text {st }}$ testing of 8 QT specimens are shown in Table 4. As noted in the table, it was hard to measure the signal amplitude and defect depth of the pre and post H2-16 specimens, due to the continuously distributed noise signals. The C-scan graphics of H2-16 and 19 specimens shows the both noise and magnetite signal not to be able to evaluate in the Fig. 8 and 9.

\subsection{Second Testing}

As mentioned in the above section 4.1, the actual components of the signal amplitude and depth of the flaw are affected by the factors including magnetite present in the QT specimens and the external noise. Thus the need to remove these interfering elements was raised. After the
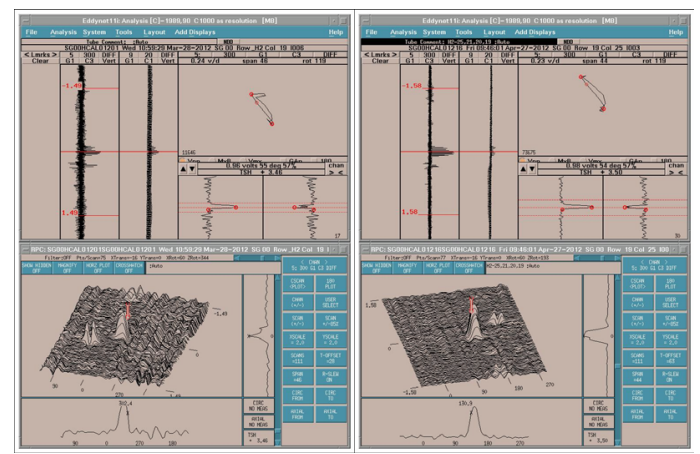

Fig. 10 EC C-scan of $2^{\text {nd }}$ QT of pre(L)/post(R) H2-13
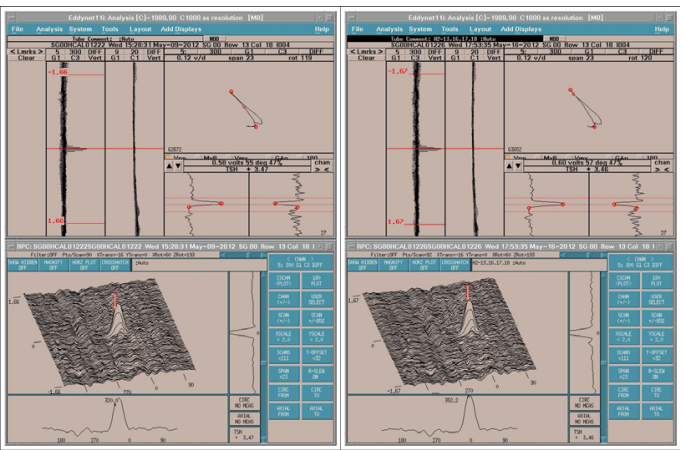

Fig. 12 EC C-scan of $2^{\text {nd }}$ QT of pre(L)/post(R) H2-17 post treatment eliminating the magnetic noise was performed, the stable ECT systems were prepared, the second experiment was undertaken and the expected better signal was obtained. The testing procedure was complied with the same as in the first experiment. The results of the testing are shown in the following Table 5.

Table 5 ECT results of $2^{\text {nd }}$ pre/post QT specimens

\begin{tabular}{|c|c|c|c|c|c|c|}
\hline \multirow{2}{*}{ Spec. } & \multicolumn{2}{|c|}{ Pre-QT } & \multicolumn{2}{c|}{ Post-QT } & \multicolumn{2}{c|}{ Deviation } \\
\cline { 2 - 7 } & Amp. & \%TWH & Amp. & \%TWH & Amp. & \%TWH \\
\hline \hline H2-13 & 0.70 & 50 & 0.73 & 51 & 0.03 & 1 \\
\hline H2-16 & \multicolumn{5}{|c|}{ Not measurable(Attributed to noise) } \\
\hline H2-17 & 0.58 & 47 & 0.60 & 47 & 0.02 & 0 \\
\hline H2-18 & 2.17 & 74 & 2.22 & 74 & 0.05 & 0 \\
\hline H2-19 & 1.04 & 58 & 1.16 & 61 & 0.12 & 3 \\
\hline H2-20 & 1.32 & 63 & 1.33 & 63 & 0.01 & 0 \\
\hline H2-21 & 1.42 & 65 & 1.53 & 66 & 0.11 & 1 \\
\hline H2-25 & 0.99 & 57 & 1.03 & 58 & 0.04 & 1 \\
\hline
\end{tabular}
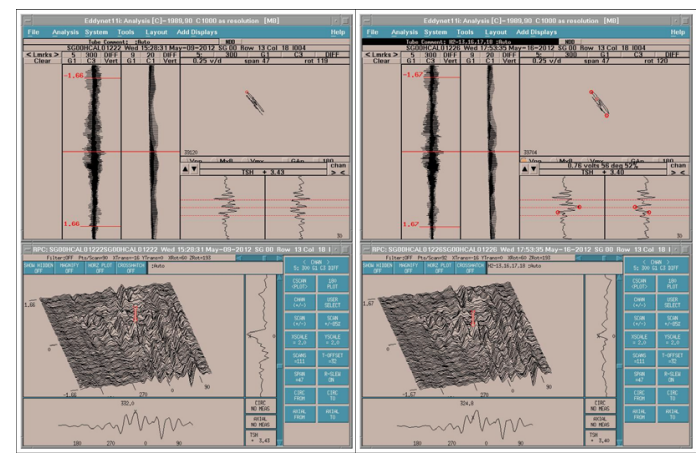

Fig. 11 EC C-scan of $2^{\text {nd }}$ QT of pre(L)/post(R) H2-16
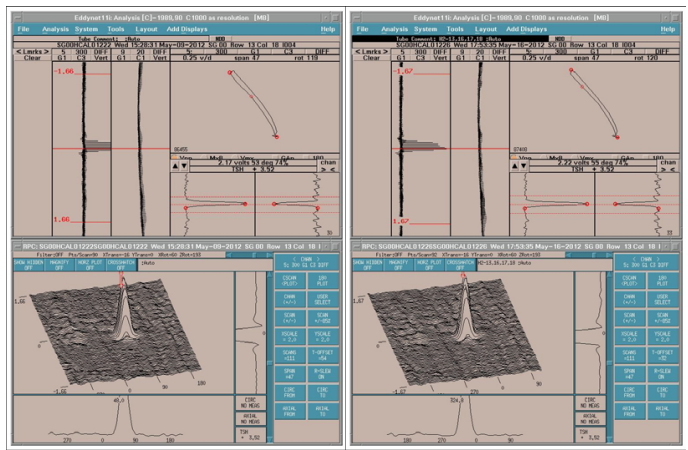

Fig. 13 EC C-scan of $2^{\text {nd }}$ QT of pre(L)/post(R) H2-18 
According to the results shown in Table 5, the difference between pre and post QT is approximately within the allowable tolerance except H2-19 and 21. These two specimens already has shown the PV properties in the first testing results. In the second experiment, the measured value of the noise signal of H2-19 specimen was dropped $2.47 \mathrm{~V}$ (pre-QT) to $1.93 \mathrm{~V}$ (post-QT), thus the decreased value of the noise signals of $0.54 \mathrm{~V}$ made the flaw signals inversely increase. This can be also applicable to the case of the H2-21 specimen. However the H2-16 specimen clustered with noise signals in the first testing showed somewhat improved signals in the second testing, nevertheless the measurement of the signal amplitude and depth was nearly impossible as estimated. The average value of the changed amplitude and depth is $0.05 \mathrm{~V}$ and 0.85 , respectively. Consequently, the variation of the amplitude, shape and depth of

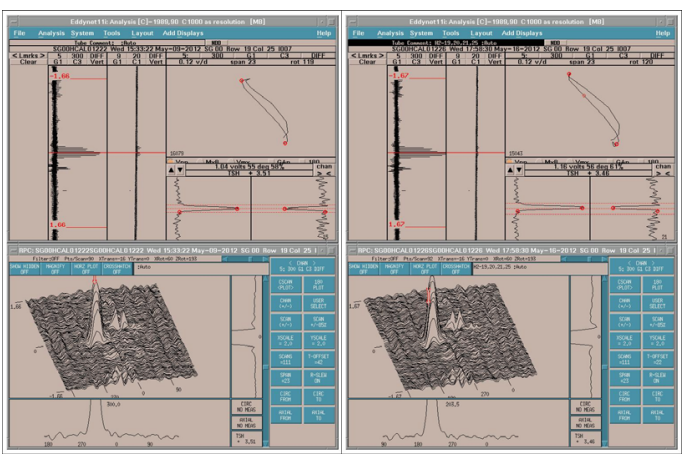

Fig. 14 EC C-scan of $2^{\text {nd }}$ QT of pre(L)/post(R) $H 2-19$

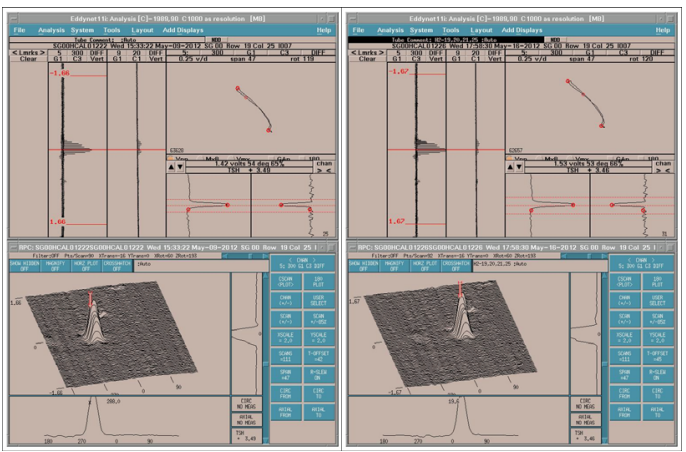

Fig. 16 EC C-scan of $2^{\text {nd }}$ QT of $\operatorname{pre}(\mathrm{L}) / \operatorname{post}(\mathrm{R}) \mathrm{H} 2-21$ the defects between pre and post QT was negligible and within the scope of the allowable tolerance, comparing with the first test results. Fig. 10, 11, 12, 13, 14, 15, 16 and 17 are EC C-scan graphics of the pre and post QT specimens of the second test.

\section{Conclusions}

The ECT to confirm the effect of the EPRI chemical cleaning process was performed for the tube specimens with an artificial crack. The tests were performed two times for getting a reliable result. In the first test, the signal amplitude and depth of the defect of the post QT specimens were slightly increased as much as $0.38 \mathrm{~V}$ and 7 of the pre QT specimens, respectively. The changes of ECT results on the specimens were presumably attributed from the distorted residual
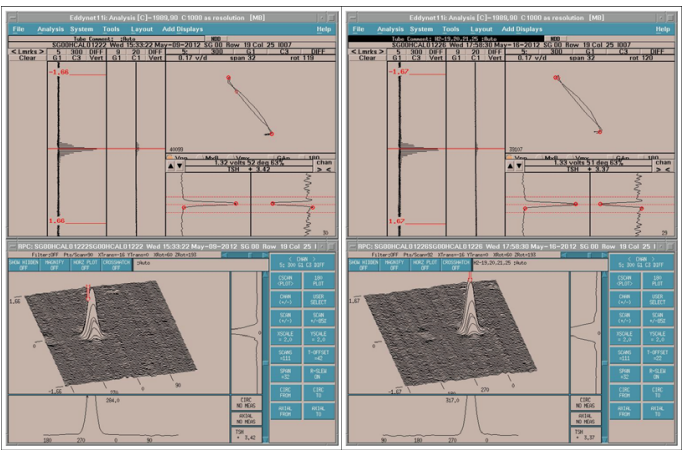

Fig. 15 EC C-scan of $2^{\text {nd }}$ QT of pre(L)/post(R) H2-20

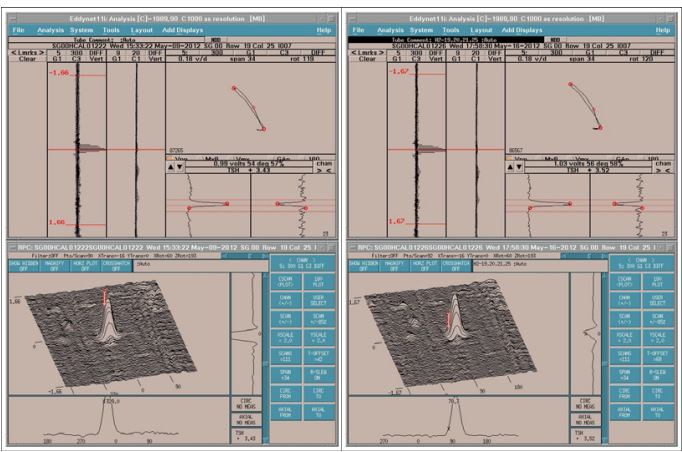

Fig. 17 EC C-scan of $2^{\text {nd }}$ QT of pre(L)/post(R) $H 2-25$ 
magnetite signal, or PV of the specimen and electromagnetic noise induced from the pre QT specimens and/or testing systems. However, in the second test, the variable factors were significantly eliminated and consequently, the test results of the pre and post QT specimens confirmed the effectiveness of the EPRI chemical cleaning process especially due to the little or no effect to the SG tubes bearing pre-cracked defect. As the chemical cleaning process has resulted in negligible impact to the integrity of the SG tubes, the application of the periodic chemical cleaning is highly recommendable especially in terms of the preventative measures of the corrosion cracking and fouling management of the SG tubes.

\section{References}

[1] Atomic Energy Society of Japan, "Handbook of Water Chemistry of Nuclear Reactor System," Corona Publishing Co. Tokyo, p. 170 (2000)

[2] S. Odar and K. Kuhnke, "The KWU chemical cleaning process as a remedial measure to improve steam generator performance," Proc. Int. Conf. Water Chemistry of Nuclear Systems, Water Chemistry 6, British Nuclear Energy Society, p. 113 (1992)

[3] H. Forch, T. Oliver and W. Hertle, "Chemical cleaning of PWR steam generators with a low temperature process," Nucl. Eng. Des., p. 147, p. 115 (1993)

[4] G. Jacobi, B. Markgraf, H. R. Sauer, K. Seidelmann and S. Odar, "KWU's hightemperature chemical cleaning process application in German PWRs to improve steam generator performance," Proc. Int. Conf. Water Chemistry of Nuclear Systems, Water Chemistry 8, British Nuclear Energy Society, pp. 207-212 (2000)

[5] B. Dow and R. Thomas, "Chemical cleaning review," Nucl. Eng. Int., p. 40, p. 38 (1995)

[6] S. Odar, "KWU high temperature chemical cleaning process control," Proc. Int. Conf. Water Chemistry of Nuclear Systems, Water Chemistry 7, British Nuclear Energy Society, pp. 335-340 (1996)

[7] H. Kawamura, K. Fujiwara, H. Kanbe, H. Hirano, H. Takiguchi, K. Yoshino, S. Yamamoto, T. Shibata and K. Ishigure, "Applicability of chemical cleaning process to steam generator side(III)," Journal of Nuclear Science and Technology, Vol. 43, No. 6, pp. 655-668 (2006)

[8] K. Fujiwara, "Applicability of chemical cleaning process to steam generator side(I)," Journal of Nuclear Science and Technology, Vol. 41, No. 1 pp. 44-54 (2004)

[9] J. M. Jevec and W. S. Leedy, "Chemical Cleaning Solvent and Process Testing," EPRI NP-2976, (1983)

[10] D. P. Rochester, D. Ltate and R. P. Dow, "Optimization of the EPRI/SGOG steam generator chemical cleaning copper solvent," Proc. Int. Conf. on Water Chemistry in Nuclear Power Plants, Water Chemistry '91, Japan Atomic Industrial Forum, Fukui, Japan, 229 (1991)

[11] Central Research Institute of KHNP, "Chemical cleaning assessment for defect tube, Rev. 0," pp 1-6 (2012) 